\title{
O papel dos consel hos gestores de políticas públicas: um debate a partir das práticas em Conselhos Municipais de Chapecó (SC)
}

\author{
The role of management councils of public polices: \\ a debate on practices in the Municipal Councils \\ of Chapecó, Santa Catarina State
}

M aria Elisabeth Kleba ${ }^{1}$

Alexandre $\mathrm{M}$ atielo ${ }^{1}$

Dunia Comerlatto ${ }^{1}$

Elisonia Renk ${ }^{1}$

Liane Colliselli ${ }^{1}$
${ }^{1}$ Grupo dePesquisa em Políticas Públicas e Participação Social, Universidade Comunitária Regional deChapecó. Rua Senador Atílio Fontana 591 E, Bairro Efapi. 89809-000 Chapecó SC.

Ikleba@unochapeco.edu.br
Abstract In this work we analyze the effectiveness of social control from a study of attributions of M unicipal Councils of: social assistance, children and teenagers' rights, health and, education in Chapecó city. The data was collected by the reading of official documents, application of questionnaires, systematic observation and a meeting in which thefocus group technique was used. Five categories of action were found: to deliberate, to supervise, to regulate, to give assistance, to communicate, and other less frequents actions. The analysis of information revels an overcharge of attributions of bureaucracy, restricting the political debate on the role of councilors. Besides this, we question the legitimacy of the conferred attributions, considering the objective conditions of its participation: the volunteer character, nonremunerated; the restrict time of the meetings the lack of qualified and self-made physical and operational structure, and others. The $M$ anagement Councils are the spaces of citizenship practice, what requires a bigger actuation in creation and strength of dialogue processes with different social actors, establishing a connection in the partner net in favor of dealing with social problems of the city and the construction of favorable conditions for life.

Key words Social participation, Social control, Public polices management
Resumo N estetrabalho, analisamosa efetividade do controle social a partir do estudo sobre atribuições dos Conselhos M unici pais da Assistência Social, dos Direitos da Criança e do Adolescente, da Educação e da Saúde no município de Chapecó (SC). O s dados foram coletados através da leitura de documentos oficiais, aplicação de formulários, observação sistemática e de um encontro utilizando a técnica do grupo focal. Foram identificadas cinco categorias de ação: deliberar, fiscalizar, normatizar, prestar assessoria, comunicar, além de outras ações menos frequentes. $A$ análise das informações revela sobrecarga de atribuições burocráticas, restringindo o debate político inerente ao papel dos consel heiros. Além disso, questionamosa legitimidade de suas atribuições, considerando as condições objetivas de sua participação: 0 caráter voluntário, não profissional, não remunerado; 0 tempo restrito dos encontros; a falta de estrutura física e operacional qualificada e autônoma, entre outras. O s consel hos gestores são espaços de exercício de cidadania, o que requer maior atuação na criação e no fortalecimento de canais e processos de diálogo com diferentes atores sociais, constituindo elos na rede de parcerias em prol do enfrentamento dos problemas sociais da cidade e da construção de condições favoráveis à vida.

Palavras-chave Participação social, Controle social, Gestão de políticas públicas 
Introdução

A Constituição de 1988 trouxe à gestão pública no Brasil grandes desafios em relação à efetivação dos direitos sociais prescritos como universais, incluindo a democratização do poder. 0 § 3o do Art. 37 da Constituição ${ }^{1}$ prevêa participação do usuário na administração pública diretae indireta, estabelecendo que a lei deverá regular especialmente:

I - as reclamações relativas à prestação dos serviços públicos em geral, asseguradasa manutenção de serviços de atendimento ao usuário e a avaliação periódica, externa e interna, da qualidade dos serviços;

II - 0 acesso dos usuários a registros administrativos e a informações sobre atos de governo [...].

A participação social na gestão pública é referida na Constituição de forma explicita em três áreas: a política agrícola, a seguridade social e a educação.

O Art. 194 estabelece como competência do poder público a organização da seguridade social, tendo como um dos objetivos o "caráter de mocrático e descentralizado da administração, mediantegestão quadripartite, com participação dos trabalhadores, dos empregadores, dos aposentados e do Governo nos órgãos colegiados". $\mathrm{Na}$ área da assistência social, o Art. 204 prevê a descentralização político-administrativa e a participação da população, por meio de organizações representativas, na formulação das políticas e no controle das ações em todos os níveis. $\mathrm{Na}$ área da educação, o Art. 206 prevê entre seus princípios fundamentais a gestão democrática do ensino público, na forma da lei.

A participação social foi institucionalizada a partir da constituição através da implantação dos consel hos gestores, espaços onde Estado e sociedadecivil compartilham o poder de decidir, instituindo uma nova cultura política e um novo modelo de gestão pública². No entanto, a efetividade destes consel hos tem sido condicionada por inúmeros fatores, desde a capacidade de formulação e negociação de propostas, até o grau de autonomia dos atores que 0 constituem. 0 que seconstata éque foram desconcentradas responsabilidades e não democratizado o poder.

Problematizando o debatesobre o cumprimento do papel dos conselhos, Demantova² analisa distorções provocadas por alguns autores, que confundem efetividade com eficácia desse espaço. A eficácia é avaliada comparando-se os resultados do processo de intervenção em relação a objetivos previamente definidos, enquanto a efetividade é avaliada pela capacidade que os atores possuem em cumprir finalidades em relação à sua missão. Neste sentido, atribuir a tais espaços o papel de agentes de transformação do Estado e da sociedade - com poder de eliminar a desigualdade e instaurar a cidadania -, e adotar tais parâmetros para avaliar sua atuação, tem provocado sentimentos de frustração em relação a seu potencial².

Fleury ${ }^{3}$ ressalta a diferença entre eficácia e efetividade da ação política dos atores envolvidos em conselhos gestores: a primeira éaval iada pela aceitação e incorporação de suas sugestões pelo Executivo e Legislativo, enquanto quea segunda pode ser vista a partir da capacidade destes atores de gerar consensos.

Buscando distinguir os conceitos de efetividade e eficácia, observamos aproximações em diferentes dicionários: a qualidade de efetivo éressaltada como aquilo queéreal, diante do queéapenas desejado, imaginado, ou possível ${ }^{4}$. Efetivar é realizar, concretizar algo; ser eficaz, por sua vez, é produzir um efeito, obtendo um resultado desejado 5 . A partir desta distinção conceitual, estabelecemos como ponto central de nossa pesquisa a análise da efetividade dos conselhos municipais em Chapecó, a partir do cumprimento das atribuições que lhe são conferidas na legislação. A ênfase, desta forma, será reconhecer a atuação do conselheiro, e não os resultados de sua atuação.

\section{Procedimentos metodológicos}

0 estudo, de caráter descritivo, foi realizado de julho de 2004 a junho de 2005, com os membros dos Conselhos Municipais da Assistência Social (COM AS), dos Direitos da Criança e do Adolescente (CM DCA), da Educação (COMED) e da Saúde (CM S) do município de Chapecó, situado na região oeste de Santa Catarina. Os conselhos estudados possuem ao todo setenta conselheiros efetivos, sendo catorze do COMAS, catorze do CM DCA, catorze do COM ED e 28 do CMS.

A pós obter o consentimento livree esclarecido dos envolvidos, procedemos ao levantamento de informações sobre os consel hos selecionados, através da aplicação de formulários e da leitura documental. A análise de documentos priorizou as leis que criaram os conselhos, seus regimentos internos e as atas das reuniões referentes ao período analisado. Para conhecer a percepção dos consel hei ros sobre seu papel, utilizamos um formulário com perguntas semiabertas, entregue aos consel heiros e recolhidos nos dias e locais das reuniões dos conselhos. 
Realizamos ainda duas observações sistemáticas em cada conselho, gravando as falas (posteriormentetranscritas), eregistrando fatos esituações deinteresse para a pesquisa. As categorias de observação foram definidas a priori, visando garantir uniformidade no processo de coleta de dados. Este instrumento foi testado em duas reuniões de cada consel ho, quando os observadores familiarizaram-se com o instrumento ea metodologia, fornecendo subsídios para sua adequação.

Após análise das informações obtidas através dos instrumentos acima descritos, realizamos um encontro aplicando a técnica do grupo focal, do qual participaram cinco dos dez conseIheiros convidados, selecionados entre os membros mais ativos. O grupo focal, diferente da observação que focaliza o comportamento e as relações, visa apreender opiniões, relevâncias e valores dos sujeitos envolvidos na investigação. No processo de interação, comentários de uns fazem emergir opiniões de outros, facilitando a expressão de emoções e de controvérsias, revelando como conflitos são abordados ${ }^{6}$.

Para a análise dos dados, utilizamos o programa Sphinxs e a técnica da análise de conteúdo ${ }^{7}$. $\mathrm{Na}$ apresentação dos dados, foram adotados pseudônimos para preservar a identidade dos participantes.

\section{Atribuições dos conselhos municipais depolíticas públicas e sua efetivação}

A legislação dos conselhos municipais pesquisados em Chapecó discrimina uma lista de atribuições ou competências que traduzem uma grande expectativa sobre a atuação de seus membros. Ao CM DCA são designadas 36 atribuições, ao CM AS, 23, ao COMED, dezenove e ao CM S, dezessete. A maior parte destas foram incorporadas de resoluções ou outros documentos delibe rados em esfera federal.

N uma primeira anál isesobreessas atribuições, identificamosgrandes categoriastemáticas, incluindo ações relacionadas: (1) às políticas do setor sobre as quais o conselho exerce seu controle; (2) às ações, serviços e programas desenvolvidos por instituições públicas e privadas; (3) às relações estabelecidas ou que devem ser construídas entre diferentes níveis de governo, entre serviços públicos e privados e com instituições deensino e pesquisa; como também (4) à promoção da participação social na gestão pública, entre outras.

A partir desta primeira delimitação, estabelecemos cinco categorias de ação que conformam a coluna vertebral de nossa análise sobre a efetivação do papel dos conselheiros, a saber:

Deliberar: revela ações como aprovar, elaborar, atuar na formulação, estabelecer ou definir critérios, fixar diretrizes, definir prioridades ou deliberar;

Fiscalizar: inclui ações como supervisionar, acompanhar, avaliar, controlar, fiscalizar, encaminhar ou examinar denúncias, promover auditorias;

Normatizar ou registrar: reúne ações como autorizar, normatizar, regulamentar, credenciar, dar posse, conceder licença, cadastrar, registrar, cancelar registro;

Assessorar ou prestar consultoria: contempla ações como apreciar contratos, assessorar, constituir comissões, participar da definição, do planejamento e da formulação, propor medidas, critérios ou a adoção de critérios;

Informar ou comunicar: indica ações como manter cadastro de informações, manter comunicação, solicitar informações, estudos ou pareceres, promover eventos ou estudos, possi bilitar conhecimento de informações, responder consultas, publicar resoluções.

Além destas categorias, identificamos outras relacionadas à coordenação, organização, incentivo e estímulo, ou ainda à solicitação de apoio e à adoção de providências que podem ser interpretadas como de caráter executivo ou não revelam com clareza seu propósito.

A Figura 1 indica a proporção que as ações, agrupadas a partir destas categorias, são previstas nos regimentos internos dos consel hos estudados.

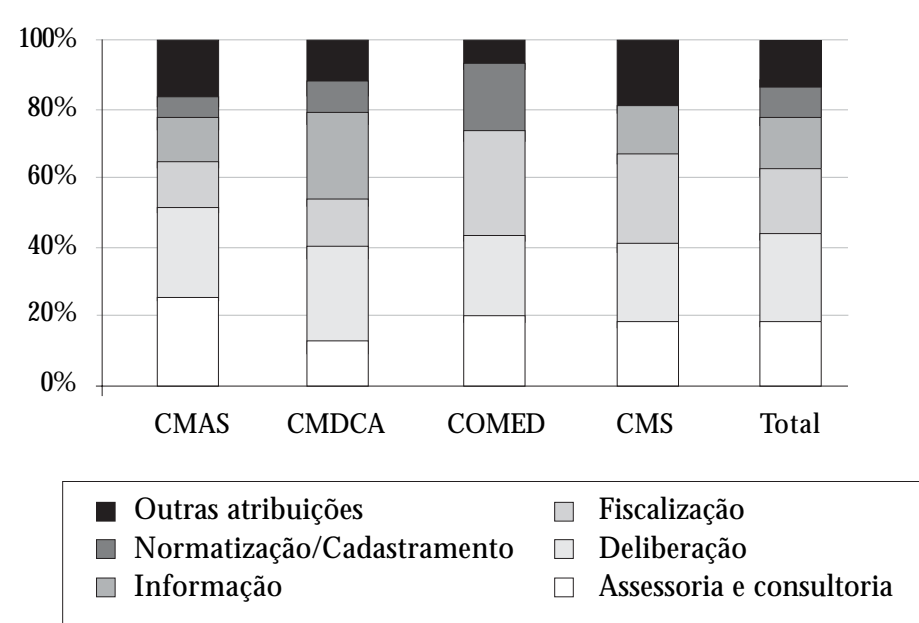

Figura 1. Proporção das ações previstas como competência / atribuição nos Regimentos Internos do CM AS, CM DCA, COMED e CM S do município de Chapecó, SC, 2005. 


\section{O papel deliberativo dos conselhos}

O papel deliberativo tem sido apontado pela própria legislação como uma das principais funções dos conselhos gestores. Se observarmos a proporção das atribuições designadas aos conselhos na Figura 1, constatamos que a ação deliberar atinge $25,19 \%$ na média dos quatro conselhos estudados, assumindo a maior proporção no CMDCA $(27,66 \%)$.

Analisando a que categorias temáticas a ação de deliberar se refere, percebemos uma grande ênfasena aprovação de questões relacionadas aos investimentos, especialmente no CM DCA: deliberar sobre concessão de recursos públicos a programas e projetos [...]; deliberar sobre política de captação de recursos e sua correta aplicação; deliberar sobre alocação de recursos a partir de prioridades definidas e seu remanejamento; deliberar sobre parâmetros técnicos e as dir retrizes para aplicação dos recursos financeiros.

Também recebe ênfase a deliberação sobre ações, programas eserviços: "deliberar [...] sobrea gestão dos recursos, os resultados sociais e o desempenho dos programase projetos sociais (CM AS e CM DCA)". A aprovação de questões, bem como a definição de diretrizes, critérios ou prioridades relacionadas à política, são enfatizadas no CM ASe no CM S: "deliberar sobre prioridades para a políticamunicipal; estabelecer diretrizes a serem observadas na elaboração do plano municipal".

Analisando a prática dos conselheiros a partir do que lhes é prescrito, destacamos al gumas dificuldades na efetivação desta competência. Um primeiro aspecto ressaltado pelos conselheiros no grupo focal éa seleção dos temas que chegam ao conselho para deliberação:

Às vezes as coi sas vem quando já aconteceram, e depois apenas entra no conselho pra discutir. (M argarida)

Tem tanta coisa que acontece a margem dos consel hos, que seria papel do conselho deliberar, e quea gente nem fica sabendo! (Camélia)

Além disso, os conselhos recebem demandas focalizadas, concentrando sobre estas seu debate:

A gente parecequefica apagando fogo. Tem um problema lá, a gente tem que correr. A dimensão maior que éa política pública, que vai dar diretrizes, a gente deixa de lado. (Rosa)

A gente não pensa num projeto, uma proposta maior dentro da política pública. A gente se detém muito ao que vem surgindo [como] necessidade. N ão tem prazo e tudo é pra ontem! (Acácia)

D esta forma, os consel hos reproduzem a lógica da gestão pública, que comumente organiza sua intervenção sobre problemas pontuais, a partir de políticas setoriais. Os atores sociais que vem ocupando a cena pública trazem, muitas vezes, a estes espaços sua visão fragmentária, reivindicativa e setorizada, ligada a interesses específicos e coorporativos, dificultando a incorporação no debate de uma visão articulada da cidade, que reconheça a complexidade da realidadee dos problemas sociais.

Um segundo aspecto restritivo é a divisão de tarefas en tre comissões, organizadas para agilizar o encaminhamento de demandas no conselho:

$\mathrm{N}$ a verdade são as comissões que discutem; que pensam, discutindo, elaborando. Depois é a aprovação. A dificuldade [é] a sobrecarga de trabalho. As pessoas que estão nos consel hos são pessoas que tem inúmeras atividades. (Acácia)

Estefluxo viabiliza maior dedicação dealguns conselheiros a temáticas específicas, que podem priorizar tempo para aprofundá-las e garantir que as decisões sejam tomadas com maior conhecimento de causa. Sendo este espaço restrito a grupos menores, é maior a probabilidade de consensos e os trâmites são mais ágeis do que quando submetidos às plenárias dos conselhos. No entanto, os pareceres das comissões não garantem, muitas vezes, informações suficientes aos conselheiros, assegurando decisões conscientes. Estes podem sentir-se não apenas desmotivados, mas também desautorizados em problematizar as decisões das comissões.

Exceto o CM S - que não dispunha na época de comissões efetivamente ativas -, nos demais conselhos, os temas colocados para deliberação são encaminhados às comissões, que então trazem seu parecer ao conselho para aprovação. Em todos os casos observados, o parecer é lido, colocado em apreciação, recebendo votação favorável por unanimidade.

Outro aspecto a problematizar é o caráter de democracia representativa dos consel hos. As deliberações ocorrem a partir de votações, sendo seu resultado definido pelas preferências da maioria presente. Em al gumas situações, presenciamos debates acirrados sobre temas polêmicos, especialmenteenvolvendo relações com os serviços privados no CMS.

O grandediferencial dos conselhos seria constituir-se em espaço de aprendizado da democracia, exercitando a formulação de consensos, uma vez que o que está em jogo é o interesse coletivo, quenem sempre coincide com o interesse de uma "maioria" presente ou ali representada. Nestesentido, o modelo da democracia deliberativa possui um potencial maior na produção de mudanças 
sociais, pois neste os participantes não se submetem a normas previamenteaceitas para eleger entre alternativas, premissa do modelo da democracia representativa, mas deliberam sobreas próprias normas que regem sua dinâmica decisória ${ }^{3}$.

A única norma previamente aceita é aquela que diz que o processo decisório coletivo deve contar com a participação de todos que serão afetados pela decisão ou por seus representantes. Este seria o componente democrático. Já o componentedeliberativo diz respeito a que o processo decisório seja feito por meio de argumentos que são oferecidos pelos participantes que estão comprometidos com os valores da racionalidade e da imparcialidade 3 .

A democracia deliberativa requer mecanismos de representação com envolvimento dosindivíduos como cidadãos ativos, construtores de consensos, por meio de diálogos realizados em processos de participação, na geração e elaboração de políticas públicas ${ }^{8}$ O processo democrático se fundamenta em regras do discurso e formas de argumentação, cuja norma se define pela ação que busca o entendimento. Este modelo requer troca efetiva de informações entre os participantes, permitindo a mudança dos pontos de vista e a geração de consensos mais amplos. "O processo decisório não é para eleger entre alternativas, mas para gerar novas alternativas, o que possibilitaria maior inovação social" ${ }^{\prime 3}$.

\section{O papel defiscalização dos conselhos}

$\mathrm{Na}$ legislação dos consel hos estudados, a fiscalização aparece em segundo lugar na média geral das atribuições, com 19,26\% (Figura 1). No $\operatorname{COMED}(30,00 \%)$ eno CM S $(25,93 \%)$, esta ação aparece em primeiro lugar. A atuação dos conseIhos nesta dimensão está predominantemente relacionada às ações, programas eserviços: acompanhar, avaliar e fiscalizar os serviços de assistência (CM AS); fiscalizar e acompanhar ações e serviços de saúde (CMS); acompanhar programas de prevenção biopsicossocial (CMDCA); acompanhar e avaliar as experiências pedagógicas; supervisionar as formas de organização e aproveitamento escolar dos estabelecimentos do Sistema Municipal de Educação (COM ED).

Em menor proporção, esta atribuiç̧ão aparece relacionada à política: acompanhar e controlar a execução da política dos direitos da Criança e do Adolescente (CM DCA); acompanhar a política de educação e o funcionamento do sistema municipal de ensino (COMED); e ao financia- mento: acompanhar a execução orçamentária; fiscalizar a movimentação e a aplicação dos recursos; acompanhar e avaliar desempenhos e resultados financeiros do fundo.

Constatamos a fiscalização sobre os serviços como atividade mais frequente, principalmente no COM ED, CM AS e CM DCA, visando regularizar situações de registro, cadastrar ou credenciar entidades que desenvolvem ações na área da competência destes conselhos. Não identificamos, no entanto, indicadores ou parâmetros de qualidade utilizados para avaliar "resultados sociais" e o "desempenho" dos programas, ou ainda para "acompanhar e controlar a execução da política", como está previsto nos regimentos destes consel hos.

No caso do COMED, por exemplo, que tem como atribuição "avaliar as experiências pedagógicas", quais os parâmetros que os conselheiros deveriam adotar para desempenhar esta atribuição, considerando as diferentes tendências pedagógicas? Esta consciência ér revelada por uma conselheira no grupo focal:

É uma polêmica muito grande. Até porquetem concepções diferentes; o que talvez pra mim éuma coisa importante, pra [M argarida] já não seja importante. Tem interesses diferentes. (Rosa)

$O$ conselho devetranscender seu papel defiscalizador, colocando em questão a própria política. 0 conselho pode melhorar a eficácia da política "se colocar em discussão seu conteúdo, os seus objetivos, as suas estratégias e prioridadese, principalmente, o público ao qual se destina" ${ }^{\prime \prime}$.

\section{O conselho enquanto órgão denormatização}

O utra atribuiç̧ão dos conselhos éa normatização e 0 cadastramento de instituições públicas e privadas. Esta ação aparece com 8,89\% em média entreos conselhos, não sendo prevista no CM S. É no COMED que esta ação aparece com maior frequência, com $17,65 \%$, como por exemplo, "normatizar a política deeducação eo funcionamento do sistema municipal de ensino; normatizar as formas de organização e aproveitamento escolar; normatizar a transferência de alunos".

Balzano et al. ${ }^{10}$ classificam as atribuições dos conselhos de educação em duas categorias: técnico-pedagógicas e de partici pação social. São as atribuições de natureza técnico-pedagógica que conferem aos consel hos sua tarefa mais rotinei$\mathrm{ra}$, entreelas aprovar estatutos eregimentos; promover sindicâncias; elaborar normas educacio- 
nais complementares; credenciar escolas; autorizar cursos, séries ou ciclos, etc. Os processos têm muitos documentos, o fluxo é lento e a análise, muitas vezes, reduz-seà verificação de papéis que nem sempre correspondem à realidade, caracterizando o conselho como órgão cartorial e burocrático ${ }^{10}$

Estas funções possibilitam aos consel heiros a aplicação de sanções - suspender matrículas, determinar a cessação de cursos ou atividades irre gulares, etc. - às instituições ou pessoas físicas que descumprem a lei ou as normas; controle também exercido sobre o poder público: constatada irregularidade, o consel ho deve pronunciarse, solicitando esclarecimento aos responsáveis, ou denunciando aos órgãos fiscalizadores, como a câmara de vereadores, o Tribunal de Contas ou o Ministério Público ${ }^{10}$.

Os consel heiros reforçaram a necessidade de cumprir este papel:

M uita gente quer o título [defilantropia] porque isso implica em muito dinheiro. Nós temos critérios rígidos. (Camélia)

Eles sabem que precisa a autorização do conseIho para o funcionamento. A renovação e autorização que vence a cada ano, as vezes dois ou três anos, só é feita a partir da visita e observação dos próprios consel heiros, pra ver setá tudo dentro das normas. ( $M$ argarida)

Porém, referem que as ações de acompanhamento, avaliação econtrole se dirigem quase que exclusivamente às entidades privadas, pois:

$\mathrm{N}$ a rede, enquanto secretaria, geralmente eles dão conta de fazer esse trabalho. Nas particularesé que há a grande demanda mesmo. ( $M$ argarida)

Para Rodrigue ${ }^{11}$, principalmente em cidades menores, os consel hos apresentam um modo de atuar ambíguo em relação ao executivo municipal. M esmo em municípios maiores, onde o grau de autonomia é mais preservado, o desconhecimento técnico do representante, os custos individuais da participação e os obstáculos colocados pela administração têm limitado a atuação dos conselheiros.

Questionados se esta atribuição não estaria exigindo dedicação da maior parte do tempo que disponibilizam ao conselho, dificultando assim a discussão sobre prioridades para o setor e outras questões mais amplas no âmbito das políticas públicas, os consel heiros posicionam-se:

Nós não temos outras pessoas, então é o próprio conselho, os consel heiros que vão fazer esse trabalho, então é necessário. ( $M$ argarida)

A gente vai lá pra melhorar e pro bem das crianças. A gente tem que fazer este papel! Porque as crianças é que não podem ficar à mercê. Às vezes a gente vai uma, vai duas, vai três, vai cinco, vai sete, vai oito vezes, tem escola que nós já fomos novevezes, eagora melhorou; a gentechega lá eaté a sala tá limpa, bem pintadinha. (Rosa)

Outros porém referem alternativas de interagir com o poder executivo:

0 ideal é ter um outro órgão que faça isso. 0 conselho não tá dando conta de toda a demanda. Porque a gente não tem uma liberação pra isso. (Acácia)

O sórgãos gestores [possuem] um setor que éo monitoramento e avaliação, que tem os funcionários pagos, com hora para ir lá e fiscalizar e dar 0 retorno pro conselho. Eu vejo impossível a gente fiscalizar todas as entidades, fiscalizar em lócustudo que tem aqui. Agora, a partir do relatório que a gente exige desse setor, sesurgiram dúvidas, aí cabe a nós irmos lá, junto com o gestor, e ver o que tá acontecendo. (Camélia)

Tais atribuições colocam estefórum em risco de concentrar seus esforços em atribuições de caráter administrativo, transformando-se num tribunal de pequenas causas que cuida de causas menores, como reflete Azanha, citado por Balzano et al. ${ }^{10}$. À medida em que o conselho concentra sua prática sobre processos burocráticos, a abordagem das questões, tanto institucionais quanto particulares, torna-se individualizada, tratando-se cada caso como caso único, descontextualizado. Não há resgate das dimensões histórica e política na análise dos problemas, que permita aos atores do controle social superar o ativismo e participar efetivamente da articulação e formulação da política institucional ${ }^{12}$.

\section{O consel ho como consultor}

Assessorar e prestar consultoria aparece em $17,99 \%$ das atribuições na legislação dos conseIhos estudados, sendo que no CM AS ela aparece com a mesma intensidade que a ação de deliberar, em primeiro lugar, com $25,81 \%$ de frequência (Figura 1).

Algumas das ações incluídas nesta categoria requerem diálogo entre o gestor ou prestadores de serviços e os conselheiros: propor mudanças nas estruturas da administração pública e das fundações para garantir a qualidade dos serviços; propor diretrizes para o funcionamento do sistema e propor convênios de mútua cooperação (CM AS); propor programas de prevenção e atendimento biopsicossocial às crianças e adolescentes (CM DCA); propor ações e metas para 
a formação de recursos humanos (COMED e CM S); ou ainda assessorar as Conferências M unicipais de Educação (COM ED).

Por outro lado, esta categoria de ação revela grande expectativa frente à atuação dos conseIheiros, pois requer competência técnica, quenem sempre é de seu domínio, como propor adoção de critérios que definam padrão de qualidade e melhor resolutividade das ações e serviços (CMS), ou propor critérios para a programação e para as execuções financeiras e orçamentárias do Fundo Municipal (CM S e CM AS), ou ainda assessorar a elaboração do orçamento do Município (COMED).

N esse sentido, uma conselheira destaca:

Às vezes, a gente se senteum pouco fora da casinha! Você está trabalhando com várias questões, ligadas a projetos sociais que às vezes até fica complicado reconhecer o nome e saber como funciona. Daí tu não tem todo aquele conhecimento que tem por traz daqueleórgão. Têm algumasquestões quea gente está realmente por fora. (H ortência)

A formulação ou a opção por critérios dequalidade ou de resolutividade tem desafiado gestores, pesquisadores e profissionais da saúde, devido ao caráter complexo destas dimensões da assistência. Da mesma forma, as questões relativas ao orçamento exigem domínio de linguagem técnica e entendimento de questões complexas. $N$ ão sepodenegar a importância de incluir outros atores sociais neste debate, de forma a permitir a reformulação dos critérios utilizados pela gestão, incorporando o significado que estes atribuem à qualidade e resolutividade, ou ainda adequando a linguagem para sua maior compreensão frente à temática. No entanto, a efetivação destas atribuições requer dos conselheiros maior qualificação, para que compreendam as implicações que suas decisões podem exercer sobre a conformação do modelo e das práticas assistenciais.

\section{A comunicação como ferramenta que potencializa o controlesocial}

A dimensão da comunicação é vital para o exercício do controle social tanto em relação à capacidade de interlocução dos conselheiros com a sociedade, quanto em sua capacidade de localizar e selecionar informações importantes, interpretá-las e utilizá-las para elaborar propostas e produzir argumentações nos processos dialógicos da participação.

Esta dimensão está prevista em 14,81\% das atribuições referidas na legislação dos consel hos estudados (Figura 1). 0 CM DCA tem esta atribuição como segunda em grau de frequência (25,53\%). Apenas o COMED não inclui ações relacionadas a esta categoria. Entre as ações previstas, ressaltamos a de manter comunicação com consel hos de outros municípios e outros níveis de governo; solicitar informações para acompanhar o fundo; realizar eventos, estudos e pesquisas integradas; manter cadastro de informações, relacionadas com seus objetivos e atribuições; divulgar e possibilitar amplo conhecimento de informações referentes ao sistema, à população e as instituições públicas e privadas; responder consultas; e ainda, publicar suas resoluções.

Esta categoria pode ser problematizada em duas dimensões: uma é a capacidade de diálogo interno, incluindo ações eestratégias para instrumentalizar os conselheiros ao exercício de suas funções. A outra é a capacidade de comunicação com os espaços externos, como as entidades ou instituições que os consel heiros representam, outros fóruns deliberativos e a sociedade em geral.

$\mathrm{N}$ as observações realizadas, constatamos momentos de conflito que justificariam maior disponibilização de tempo para diálogo, em que os atores pudessem aprimorar sua capacidade de comunicação. Ouvir o outro eser ouvido com interesse nem sempre é a prática dos consel heiros, em geral mais preocupados com que suas propostas e seus argumentos sejam acatados e "vencedores" do debate. A postura do coordenador na condução das reuniões também pode dificultar o debate democrático. Esta situação pode ser percebida na seguinte sequência:

Coordenador: Eu acho que vou interromper porque o senhor tá entrando num debate, não tá?

Conselheiro 1: É só pra esclarecer umas coisas que podem ser mais esclarecidas.

Coordenador: Então vamos marcar tempo pra ele. M ais uns dois segundos.

Conselheiro : [...]

Conselheiro 2: A gente vem aqui para aprovar, daí tem um assunto que não tem nem nexo!

Conselheiro 1: A senhora sai daqui esclarecida.

Conselheiro 2: Você começa a falar, e cada vez acumulando mais.

Conselheiro 3: Eu acho que teria que estar...

Conselheiro 2: Você pensa que aqui...

Conselheiro 4: Pessoal, eu acho que é respeito pelos consel heiros, ea fala dos consel heiroséboa. 0 consel heiro 1 fez uma explicação aqui que éválida. Todos nós aqui trabalhamos pelo bem da comunidade, ninguém aqui tá contra a comunidade.

Coordenador: Isso? 0 conselheiro 2 quer entrar nesse ponto também, daí vamos encerrar. 
Consel hei ro 2: N ós somos conselheiros e temos posições diferentes. Eu não me considero não esclarecida. Acho que todos têm posições diferentes. Eu não tenho necessidade de esclarecimentos, porque eu entendo a posição do privado, do público e a posição do governo, e cada um tem posição diferente. Eu acho que é chato os conselheiros "não serem esclarecidos" ! É uma forma de menosprezar a capacidade intel ectual de entendimento, as posições dos consel hei ros que aqui estão!

Conselheiro 1: Eu ... só um pouquinho!

Coordenador: Não, por favor! I sso aqui não é um debate.

Conselheiro 1: Essa senhora não pode sair daqui achando que eu menosprezei a senhora!

Coordenador: $\mathrm{M}$ as o senhor menosprezou! Então nós não temos porque entrar neste debate, porquenós discordamos. Não é uma questão de esclarecimentos enós discordamos. E essa di vergência a gente não vai resolver na reunião do conselho, isso não está em pauta, vamos encaminhar o que é importante.

Considerar o consel ho como "palco de disputa" podejustificar a opção por práticas de confronto entre alternativas necessariamente excludentes, alimentando o distanciamento entre seus participantes. A responsabilidade dos conselheiros se refere à deliberação sobre políticas públicas que dizem respeito ao coletivo, o que requer destes o exercício de debates ao invés deembates, diálogo e consenso ao invés de disputa de interesses e de projetos.

A ação comunicativa expressa reciprocidade einteração na intencionalidade do diálogo. A interação busca compreensão e consenso sobre uma situação, através da negociação eda abertura: os atores revelam sua forma de compreender o mundo e contam com a abertura do outro, permitindo, ao mesmo tempo, que o outro revele sua compreensão.

M orin ${ }^{12}$ enfatiza quea democracia supõeenutrea diversidadeea pluralidade deinteresses eidéias. São os conflitos de idéias que conferem vitalidadee produtividadeà democracia. A democracia nutre se da autonomia dos indivíduos, de sua liberdade de opinião e expressão, mas também de seu civismo em prol da convivencialidade. Compreender significa apreender em conjunto, incluindo "um processo de empatia, de identificação e de projeção. Sempre intersubjetiva, a compreensão pede abertura, simpatia e generosidade"12.

D efender a necessidade de diálogo não significa negar as disputas de interesse ou o poder diferenciado dos atores para influenciar opções no conselho. Significa antes reconhecer que as concepções e opções são históricas, traduzindo saberes, cren ças e valores degrupos enão podem ser classificadas entre duas posições dicotômicas na relação entreo "bem" eo "mal", entreo "certo" e o "errado".

Sendo estratégia essencial na promoção da democracia participativa, o exercício do diálogo constitui-se também em desafio aos conselheiros como interlocutores das entidades que estes representam. Neste sentido, os consel heiros em Chapecó mostram-se preocupados em relação a pouca capacidade em efetivar seu papel de mediador enquanto representantes de entidades:

Q uando a gente cai nessa questão da representação, cai sempre nessa polêmica: como tu vai discutir com seus pares, como tu vai fazer a devolutiva pra quem você representa? (Camélia)

Eu represento os pais. Como é que eu vou me organizar pra levar pros pais o quea gente discute? Não é muito fácil. Demanda trabalho, demanda agenda. A gentechama um público pra falar, a gente vai ter que ter elementos, ter clareza. (Rosa)

A participação efetiva se inviabiliza à medida quenão houver exercícios anteriores, concretos, através dos quais se aprenda e se conquiste acesso aos níveis decisórios de intervenção. Como esperar que os consel heiros atuem democraticamente se a democracia é uma prática estranha no cotidiano; sequer internamente as entidades contam com estruturas participativas e as comunidades não dispõem de espaços significativos de intervenção nas políticas públicas ${ }^{13}$.

A pesar das dificuldades enfrentadas na efetivação de processos de comunicação, os conseIhos se constituem em espaço de aprendizado da cidadania, o que é confirmado no grupo focal:

A participação pra mim é uma escola. É uma escola de vida também, pra aprender a questão da própria participação, da democracia, das perdas e ganhos, do recuo, avanço, enfim das lutas políticas, das forças quetambém estão representadas ali no conselho. (Camélia)

\section{Outras atribuições dos Consel hos}

Finalmente, $13,33 \%$ das ações previstas na legislação dos conselhos estudados são caracterizadas como outras atribuições (Figura 1), contemplando ações relacionadas à promoção da participação social como convocar, coordenar e participar da organização das conferências municipais (CM S e CM AS); estimular e garantir a participação e o controle comunitário, nas instâncias col egiadas gestoras; estimular e apoiar a orga- 
nização de Conselhos Locais de Saúde (CM S). Outras atribuiç̧ões nessa categoria estão voltadas à qualificação das ações e serviços, como estimular eincentivar a atualização permanentedos servidores e funcionários (CM AS e CM DCA); promover articulação com órgãos de fiscalização do exercício profissional e outras entidades representativas da sociedade civil, para a definição e controle dos padrões éticos para pesquisa e prestação de serviços de saúde; articular-se com os demais órgãos colegiados do Sistema Único de Saúde (CMS); contribuir na articulação e colaboração entreos Sistemas deEnsino (COM ED).

Estas atribuições são, em sua maioria, de caráter executivo, para as quais os conselheiros necessitam não apenas de disponibilidade, mas principalmente de estrutura operativa. Em nosso estudo, não evidenciamos seu exercício. Sabe mos, no entanto, que os conselhos têm exercido um papel importante na organização e realização das conferências de caráter municipal ou re gi onal, como também na articulação para a participação de conselheiros nas conferências estaduais e nacionais.

Enfatizando a necessidade de investir em estratégi as de interação com a sociedade, para viabilizar e estimular a participação de outros atores no controle social, um consel heiro reflete no grupo focal:

Nós não seremos eternos no consel ho. Tem que ter outras pessoas já sendo preparadas para assumir os próximos conselhos, pra chegar em momento de assumir e saber por onde andar. Nós precisamos começar a ajudar que outros também pensem e que as pessoas gostem, que queiram, tenham a vontade de entrar no consel ho e ajudar a construir essa cidade. ( $M$ argarida)

A efetividade da institucionalização do controle social implica também em garantir mecanismos de fomento e diálogo com as organizações sociais, a fim de ampliar e potencializar sua esfera de ação eo envolvimento da sociedade ${ }^{14}$. É necessário democratizar o espaço dos consel hos para evitar que estes reforcem e legitimem o poder instituído, fortalecendo estruturas privadas (inclusive nos espaços públicos) e a tradição clientelista ${ }^{13}$. Isto requer a implementação deestratégias de aliançase demobilização, essenciais para produzir rupturas e novas articulações coletivas.

0 próprio conselho constitui-se em espaço propulsor de cultura cívica e capital social, podendo desempenhar um papel significativo na mudança da sociedade. No entanto, a realização deste potencial depende do quanto os conselhei- ros se comprometem com a publicização de suas ações e com a criação de espaços descentralizados, aproximando-os da população, organizada ou não, visando estimular processos de organização e mobilização ${ }^{14}$.

\section{Consideraçõesfinais}

A partir desteestudo, constatamos a necessidade de revisão do papel dos conselhos gestores em nível municipal. Primeiro, o grande número de atribuições, especial mente voltadas à aprovação, autorização e fiscalização de ações e serviços, em âmbito setorial quelhes diz respeito, sobrecarrega os atores engajados e praticamente inviabiliza que estes realizem e aprofundem debates sobrea política, deliberando sobre prioridades a partir demetas a médio elongo prazo. Segundo, acomplexidade inerente a muitas das atribuições conferidas aos consel heiros nos faz questionar a legitimidade desta designação, considerando as condições concretas e objetivas previstas para sua participação efetiva: o caráter voluntário - não profissional/não remunerado - ; o tempo restrito previsto para os encontros; a falta de estrutura física e operacional qualificada e autônoma, entre outras.

Por outro lado, se defendemos que estes fóruns são espaços de exercício de cidadania e democratização do poder, os conselheiros devem ampliar sua atuação no campo da comunicação, qualificando sua capacidade de acessar e processar informações, criando e fortalecendo canais e processos de diálogo com diferentes atores sociais. Ampliar e fortalecer a participação social requer que os conselhos se constituam em elos de ligação na rede de parcerias em prol da construção de condições favoráveis à vida.

Para viabilizar maior eficácia de sua atuação, ou seja, maior impacto de suas deliberações sobreas políticas públicas, o rol de atribuições deve prever efavorecer o potencial efetivo da participação cidadã na gestão municipal. Os conselheiros devem ser liberados para dedicar maior tempo ao debate sobre questões políticas; para estudar, propor e deliberar sobre prioridades, que superem as demandas da rotina de "apagar incêndios". Para se constituir em espaços de debate democrático, os consel hos gestores devem viabilizar que atores sociais com diferentes interesses dial oguem sobre concepções e projetos e aprendam a consensuar em favor de interesses coletivos. 


\section{Colaboradores}

ME Kleba trabalhou na análise dos dados e na redação do artigo; A M atielo, D Comerlatto, E Renk eL Colliselli trabal haram na coleta de dados. Todos atuaram na discussão e revisão do artigo.

\section{Agradecimentos}

Os autores agradecem a Lucélia Razera, Lenir Rodegheri Trevisan e Tatiana Sexto pela participação na coleta de dados. Este artigo resulta de uma pesquisa que teve apoio financeiro da FAPESC e da UNOCHAPECÓ.

\section{Referências}

1. Brasil. Constituição da República Federativa do Brasil: promulgada em 5 de outubro de 1988. 21a ed. São Paulo: Saraiva; 1999.

2. Demantova GC. A eficácia dos conselhos gestores: estudo de caso do conselho municipal de desenvolvimento rural de Campinas - SP [dissertação]. Campinas (SP): U nicamp; 2003.

3. Fleury S. Concertação e efetividade da ação política: o Conselho de Desenvolvimento Econômico e Social do governo Lula. In: Anais VIII Congreso Internacional del CLAD sobre la Reforma del Estado y de la Administración Pública; 2003; Panamá.

4. Abbagnano N. Dicionário de Filosofia Política. São Paulo: M artins Fontes; 2000.

5. Ferreira $A B H$. N ovo Aurélio Século XXI: 0 dicionário da língua portuguesa. Rio de Janeiro: Nova Fronteira; 1999.

6. Westphal MF, Bógus CM, Faria MM. Grupos focais: experiências precursoras do uso da técnica em programas educativos em saúde no Brasil. Bol Oficina Sanit Panam 1996; 120(6):472-482.

7. Bardin L. Análise de conteúdo. Lisboa: Edições 70; 1995.

8. Gohn MG. Conselhos gestores e participação sociopolítica. São Paulo: Cortez; 2001.

9. Raichelis R. A relação entre os Conselhos e os movimentos sociais. In: Souto ALS; Paz R organizadores. Seminário Articulação entre os Conselhos M unicipais: Anais. São Paulo, Instituto Pólis/PUCSP; 2003. p.21-29.

10. Balzano S, Zanchet V. Organização dos Conselhos Municipais de Educação. In: Ministério da Educação. Programa Nacional de Capacitação de ConseIheiros M unicipais de Educação Pró-Conselho: guia de consulta. Brasília: M inistério da Educação/Secretaria de Educação Básica; 2004. p. 11-38.

11. Rodriguez V. Financiamento da educação e políticas públicas: o FUNDEF e a política de descentralização. Cadernos Cedes 2001; 21(55):42-57.

12. M orin $\mathrm{E}$. Os sete saberes necessários à educação do futuro. 3a ed. São Paulo: Cortez; Brasília: UNESCO; 2001.

13. Scheinvar E. Os conselhos gestores da política para a infância e a adolescência. Sociedade em debate 2003; 9(2):119-136.

14. Santos M RM. Conselhos M unicipais: a participação cívica na gestão das políticas públicas. Rio de Janeiro: Fase; 2002.

Artigo apresentado em 12/03/2007

Aprovado em 04/08/2007 